\title{
Addition effects of imidazolium salts on mesophase structure and optical properties of concentrated hydroxypropyl cellulose aqueous solutions
}

\author{
Ryotaro Chiba, Mitsuhiro Ito and Yoshiyuki Nishio
}

\begin{abstract}
Addition effects of $\mathrm{N}$-alkyl-substituted methylimidazolium salts ([CnMim][X]) on the mesophase structure and lower critical solution temperature (LCST)-type phase-separation behavior of concentrated hydroxypropyl cellulose (HPC) aqueous solutions were investigated mainly by spectrophotometry. In the cholesteric mesophase formation, at concentrations of more than 50 wt\% HPC, helical pitch $(P)$ was confirmed to shift upward according to the chaotropic strength of $X^{-}$, for example, in a manner satisfying the order of $\mathrm{Cl}^{-}<\mathrm{Br}^{-}<\mathrm{NO}_{3}{ }^{-}<\mathrm{I}^{-}$. Organocations generally elevated $P$ relative to the nonionic reference, the effectiveness being pronounced in the order of $[\mathrm{C} 2 \mathrm{Mim}]^{+}<[\mathrm{C} 4 \mathrm{Mim}]^{+}<[\mathrm{C} 6 \mathrm{Mim}]^{+}$. With regard to $\mathrm{LCST}$ behavior, imidazolium additives raised the cloud point $\left(T_{\mathrm{c}}\right)$ in the isotropic solutions of $\leqslant 40 \mathrm{wt} \% \mathrm{HPC}$, whereas the $T_{\mathrm{c}}$ value of mesomorphic solutions was prone to be lowered by the addition. Discussion of these observations took into consideration the differences in the $\mathrm{N}$-alkyl structure and amphiphilic nature between cationic imidazolium varieties, as well as the difference in the chaotropic strength between the counter anions. It was also exemplified preliminarily that this kind of salt-containing lyotropic system of HPC exercised an electro-optical function when coupled with an electric circuit.
\end{abstract}

Polymer Journal (2010) 42, 232-241; doi:10.1038/pj.2009.338; published online 13 January 2010

Keywords: cholesteric pitch; HPC; imidazolium salt; LCST behavior; liquid crystal

\section{INTRODUCTION}

It is well known that cellulosic polymers are capable of forming a cholesteric type of liquid-crystalline phase in a condensed fluid state, most probably originating from some degree of rigidity and a chiral nature in the molecular structure. ${ }^{1-4}$ Hydroxypropyl cellulose (HPC) is a representative liquid-crystalline cellulose derivative, and it can assume that type of mesomorphic state in a variety of common solvents ${ }^{1,5-8}$ and even in the melt. ${ }^{9}$ Cholesteric mesophases often impart a color because of selective light reflection, when the pitch in the supramolecular helical structure is comparable to wavelengths of visible light. HPC solutions in water exhibit such a typical optical character at polymer concentrations of ca. $50-70 \mathrm{wt} \%{ }^{5,10}$ Aqueous HPC solutions also show a phase-separation behavior with the lower critical solution temperature (LCST) usually located at $<45^{\circ} \mathrm{C}$, $5,11,12$ and therefore they become turbid on heating.

As shown in our previous studies, ${ }^{13-15}$ the cholesteric structure and LCST-type phase-separation behavior, and the ensuing optical properties of the lyotropic system of HPC in water, are significantly affected by the addition of a small amount of inorganic salts as the third component. For instance, when $\mathrm{LiCl}$ is dissolved in the cholesteric system, the wavelength $\left(\lambda_{\mathrm{M}}\right)$ of maximal light reflectance and the cloud point $\left(T_{\mathrm{c}}\right)$ shift, respectively, to the blue side and to the lower- temperature side. In contrast, the presence of LiSCN results in a red shift in $\lambda_{\mathrm{M}}$ and an elevation in $T_{\mathrm{c}}$. As a universal rule, the optical parameters $\lambda_{\mathrm{M}}$ and $T_{\mathrm{c}}$, and therefore the cholesteric pitch $(P)$ and the phase-separation temperature, were found to vary systematically with a change in strength of a so-called 'chaotropic' effect of the ions constituting the additive salts. Generally an increase in ionic chaotropicity weakens the hydrophobic interaction of (the side chains of) water-soluble polymers.

From a practical point of view, the above result implies that the coloration and turbidity of the aqueous HPC lyotropic system can be controlled desirably by selecting the combination of cation and anion species of the added salt. As an application, our current study ${ }^{16}$ dealt with the preparation of cholesteric $\mathrm{HPC} /$ methacrylate polymer networks in a colored film form and showed that the visual appearance of films was widely changeable by impregnation with various salt solutions. Furthermore, by using an electrophoretic motility of the coexistent ions as $P$ and/or $T_{c}$ shifters, the dynamic variation in cholesteric coloration and/or optical turbidity of the HPC lyotropics, including solutions and gels, were realized under application of a relatively weak electric field. ${ }^{15-18}$

Meanwhile, recently, low-temperature molten organosalts, that is, the so-called ionic liquids, have become a subject of great interest in 
various fields of chemistry, because of their possibilities as a green solvent, a new component of ion-conductive materials and so on. ${ }^{19-22}$ Representative examples of the conventionally used ionic liquids are salts with $N, N^{\prime}$-dialkylimidazolium, $N$-alkylpyridinium, alkylammonium and alkylphosphonium as the cationic moiety. In cellulose research too, much attention has been paid to the usefulness of such ionic liquids as solvents to dissolve and functionalize unmodified cellulose and related natural polysaccharides. ${ }^{23-28}$ In an extension of our preceding studies, similar ionic liquids may also be expected to function as an active mediator to control the structure and properties of the cellulosic liquid-crystalline system.

This paper describes the effects of $N$-alkyl-substituted imidazolium salts as a new series of additives on the cholesteric mesophase formation and ensuing optical properties of HPC aqueous solutions, in comparison with the previous case using alkali-metallic salts. Special care will be taken with regard to the amphiphilic structure associated with a surfactant-like activity of the voluminous organic cations used.

\section{EXPERIMENTAL PROCEDURE}

\section{Polymer material}

The powdered HPC used was a commercially available sample (Scientific Polymer Products (Ontario, NY, USA)): weight-average and number-average molecular masses, $M_{\mathrm{w}}=11.9 \times 10^{4}$ and $M_{\mathrm{n}}=4.4 \times 10^{4}$, respectively (from GPC measurements); degree of side-group substitution, $\mathrm{DS}=2.06$ and $\mathrm{MS}=4.04$ (from hydrogen-1 $\left({ }^{1} \mathrm{H}\right)$ and carbon-13 $\left({ }^{13} \mathrm{C}\right)$ nuclear magnetic resonance (NMR) measurements), ${ }^{29}$ where DS and MS denote an average number of substituted hydroxyls and that of introduced hydroxypropyl groups, respectively, per anhydroglucose residue. (In this study, the DS value of the HPC sample was determined on the basis of ${ }^{1} \mathrm{H}$ NMR data according to a method proposed by Ho et al..$^{29}$ Some of the previous articles ${ }^{13,17,18}$ reported DS $=1.8$ for the same grade (Lot\#5) of HPC from the same commercial origin; the value was determined by quantitative-mode solid-state ${ }^{13} \mathrm{C}$ NMR measurements. $)^{30}$

\section{Synthesis of imidazolium salts}

Except for 1- $n$-butyl-3-methylimidazolium nitrate ([C4Mim] $\left.\left[\mathrm{NO}_{3}\right]\right)$ purchased from Fluka (Sigma-Aldrich, Tokyo, Japan), all $\mathrm{N}$-substituted imidazolium salts used as additives were synthesized through $N$-alkylation/ quarternization of 1-methylimidazole with different alkyl halides (see Scheme 1), by reference to literatures. ${ }^{3-33}$ For instance, the procedure to obtain 1-ethyl-3-methylimidazolium bromide ([C2Mim] $[\mathrm{Br}])$ was as follows: 1-methylimidazole $(0.076 \mathrm{~mol})$ was dissolved in dry toluene $(30 \mathrm{ml})$ at room temperature, and ethylbromide $(0.228 \mathrm{~mol})$ was added to the solution at adequate time intervals. The mixture was stirred at $70^{\circ} \mathrm{C}$ for $3 \mathrm{~h}$ in a roundbottomed flask equipped with a reflux condenser under a dry $\mathrm{N}_{2}$ atmosphere. The upper phase containing unreacted reagents was decanted, and the residual crude product was washed with hot toluene lightly and then with ethyl acetate thoroughly by the combined use of stirring and ultrasonic treatment. After decanting of ethyl acetate, the remaining solvent was removed by heating the ionic liquid phase to $70{ }^{\circ} \mathrm{C}$ and stirring while on a vacuum line.

Two major salt series of 1- $n$-alkyl-3-methylimidazolium halide, [CnMim] [Br] $(n=2,4,6 ; n$, carbon number of 1-alkyl substituent $)$ and [C4Mim] [X] $(\mathrm{X}=\mathrm{Cl}, \mathrm{Br}, \mathrm{I})$, were assorted. In addition, 1-(2-hydroxyethyl)-3-methylimidazolium bromide ([C2OHMim $][\mathrm{Br}])$, 1-(6-hydroxyhexyl)-3-methylimidazolium bromide ([C6OHMim][Br] ), 1-sec-butyl-3-methylimidazolium bromide ([s-C4Mim] $[\mathrm{Br}])$, 1-isobutyl-3-methylimidazolium bromide ([i-C4Mim $][\mathrm{Br}])$ and 1,4-bis(3-methyl-1-imidazolio)butane dibromide ([MimC4Mim] $[\mathrm{Br}]_{2}$ ) were synthesized in a similar manner as above, with the respective relevant reagents instead of $n$-alkylhalides. The salt products thus obtained were all identified as the respective objects of $\mathrm{N}$-substituted methylimidazolium halides by ${ }^{1} \mathrm{H}$ NMR spectral measurements.

\section{Preparation of salt-containing HPC solutions}

HPC solutions of different polymer concentrations (10-67.5 wt\%) were prepared by mixing weighed HPC dry powder and distilled water containing a prescribed amount of imidazolium salt in a glass vial over a period of 4 weeks. During this period, the vials were usually stored in a refrigerator $\left(<4{ }^{\circ} \mathrm{C}\right)$; however, they were sometimes turned upside down in a centrifuge for the purpose of accelerating the dissolution of HPC. Throughout this study, the polymer concentration is denoted by weight $\%$ of HPC with respect to the (HPC+water) content in each solution, and the salt concentration is designated as mol per gram HPCaq in terms of a molar amount of the salt per gram of HPC aqueous solution.

\section{Measurements}

Selective light reflection of cholesteric liquid crystals was examined by visual observations, and the quantitative measurements of reflection bands were taken with an ultraviolet-visible spectrometer (Hitachi U-2001, Hitachi, Tokyo, Japan) equipped with a thermoregulated cell holder. The samples were usually encapsulated in a glass cell of $500 \mu \mathrm{m}$ thickness and then allowed to equilibrate for at least $12 \mathrm{~h}$ before measurement. An LCST-type phase-separation behavior of HPC solutions was also examined in the same apparatus. Apparent light absorbance $(A)$ as a measure of turbidity was recorded as a function of temperature, with an appropriate wavelength (usually $750 \mathrm{~nm}$ ) at which no selective reflection of the sample took place. Cloud point $T_{\mathrm{c}}$ was determined as a temperature at which $A^{2}$ reached 0.050 , for the sake of convenience.

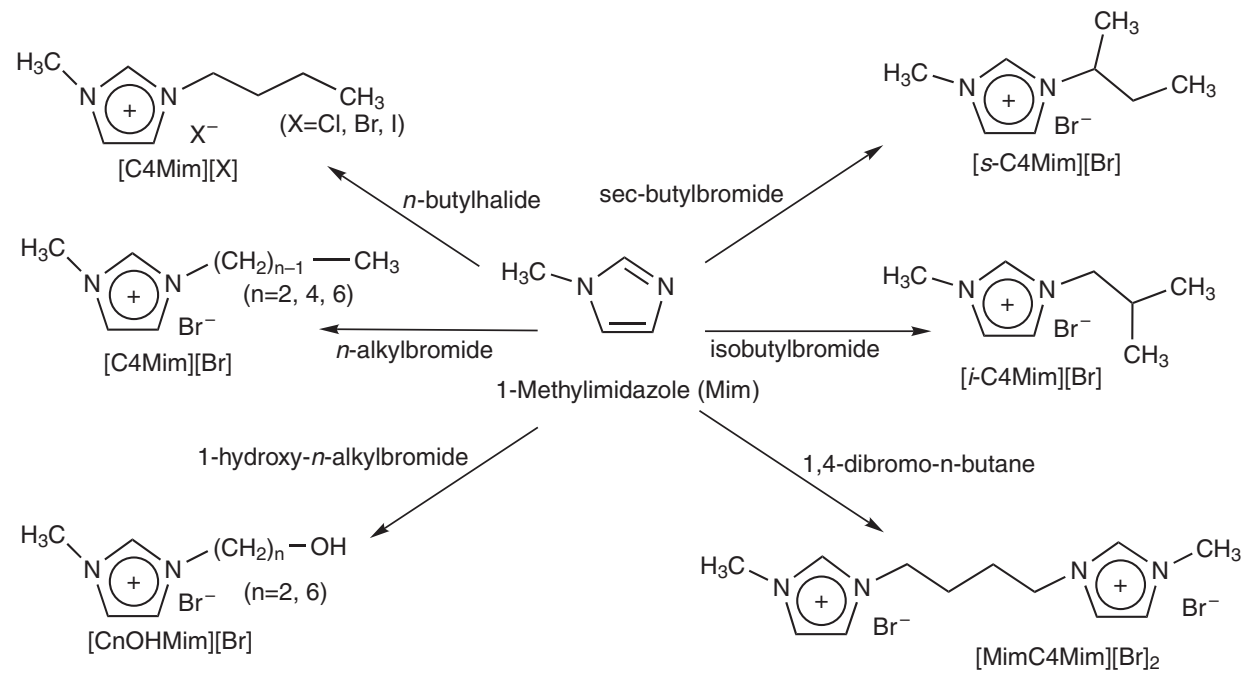

Scheme 1 Synthesis of diverse $\mathrm{N}$-substituted methylimidazolium salts. 
Apparent circular dichroism spectra were recorded for selected samples at $20^{\circ} \mathrm{C}$ with a Jasco J-820DH spectropolarimeter (Jasco, Tokyo, Japan) equipped with a Peltier-type temperature controller PTC-423L to determine the handedness of the cholesteric helical structure. Refractive index measurements were carried out using an Abbé refractometer (Atago (Tokyo, Japan) Type 2T) with a rotatable polarizer mounted over the eyepiece. For anisotropic solution samples, the principal refractive indices parallel $(n \|)$ and perpendicular $(n \perp)$ to the plane of the prism surfaces were read off.

Wide-angle X-ray diffraction (WAXD) measurements were made with a Rigaku Ultima-IV diffractometer (Rigaku, Osaka, Japan) at $10^{\circ} \mathrm{C}$ in a reflection mode. Nickel-filtered $\mathrm{CuK} \alpha$ radiation was used at $40 \mathrm{kV}$ and $40 \mathrm{~mA}$. Fluid samples were loaded into a copper holder $0.50 \mathrm{~mm}$ high and covered with a polyethylene thin film. The diffraction intensity profiles were collected in the range of $2 \theta=4-20^{\circ}$.

To observe an electro-optical effect, salt-containing aqueous HPC liquid crystals were sealed in a layered solution between parallel glasses spaced by a pair of carbon plates $500 \mu \mathrm{m}$ thick as inert electrodes. The two plates were laid on both sides of the layered solution so that their sectional planes were apart face to face at a distance of 7.5-10 mm with the aid of another sealing Teflon spacer. An electric generator, Multifunctional Synthesizer 1946 (NF Electric Instruments, Tokyo, Japan), was used to electrify the sample-charged cell. The electromotive force applied was usually $2.5-3.5 \mathrm{~V}$.

\section{RESULTS AND DISCUSSION}

\section{Selective light reflection and cholesteric helical pitch}

In accordance with earlier reports, $5,10,13$ the HPC used dissolved in water at high concentrations of $50-67.5 \mathrm{wt} \%$ to form a cholesteric supramolecular assembly; the resulting anisotropic solutions were iridescently colored due to the selective light reflection in a range of visible wavelengths. A matter of interest is how this optical property of the cholesteric HPC solutions is affected by addition of a series of imidazolium salts as the third component. For example, a $62.5 \mathrm{wt} \%$ HPC solution in normal water was indigo blue at $10^{\circ} \mathrm{C}$, but the addition of $[\mathrm{C} 4 \mathrm{Mim}][\mathrm{Br}]$ caused a change in the reflection color into orange through to bluish green, as the salt concentration was increased from $2.5 \times 10^{-5}$ to $2.5 \times 10^{-4} \mathrm{~mol}$ per gram HPCaq. Figure 1 displays light-reflection spectra for the corresponding HPC/[C4Mim][Br]/ water system. It is shown explicitly that the wavelength $\left(\lambda_{\mathrm{M}}\right)$ of maximum reflection intensity shifts to the red side with increasing salt concentration in the liquid-crystalline system at a fixed polymer concentration $(62.5 \mathrm{wt} \%)$ and temperature $\left(10^{\circ} \mathrm{C}\right)$. When the salt concentration exceeded $7.5 \times 10^{-4}$ mol per gram HPCaq, the reflection

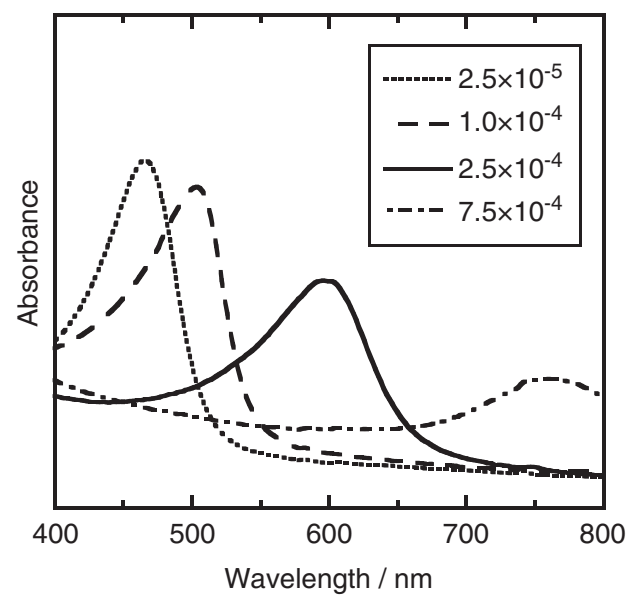

Figure 1 Selective light-reflection spectra obtained for cholesteric liquidcrystalline $\mathrm{HPC} /[\mathrm{C} 4 \mathrm{Mim}][\mathrm{Br}] /$ water solutions at $10^{\circ} \mathrm{C}$, showing a comparison between different salt concentrations at a fixed HPC concentration of $62.5 w t \%$. band of the HPC solution was situated outside the visible range, and, therefore, the cholesteric sample was visually uncolored.

Figure 2 compiles light-reflection spectra obtained at $10{ }^{\circ} \mathrm{C}$ for two series of aqueous HPC liquid crystals that contain a salt of (a) $[\mathrm{C} n \mathrm{Mim}][\mathrm{Br}](n=2,4,6)$ or (b) $[\mathrm{C} 4 \mathrm{Mim}][\mathrm{X}]\left(\mathrm{X}=\mathrm{Cl}, \mathrm{Br}, \mathrm{NO}_{3}, \mathrm{I}\right)$, both series being prepared at fixed concentrations of polymer $(62.5 \mathrm{wt} \%)$ and salt $\left(2.5 \times 10^{-4} \mathrm{~mol}\right.$ per gram HPCaq). Figure $2 \mathrm{a}$ shows that the selective reflection phenomenon of the aqueous HPC lyotropics is seriously affected by the $N$-alkyl chain length of the utilized imidazolium cation. In comparison with the situation of an additive-free sample giving a reflection band centered at ca. $475 \mathrm{~nm}$, the wavelength $\lambda_{\mathrm{M}}$ shifts to the red side in spectrum with an increase in the carbon number $(n)$ of the $N$-alkylsubstituent; that is, $\lambda_{\mathrm{M}}=507,602$ and $715 \mathrm{~nm}$ for $n=2,4$ and 6 , respectively, of the [CnMim][Br]containing series. Figure $2 \mathrm{~b}$ shows a similar comparison between four imidazolium salts of mutually different anion species. We find an order, salt free $<[\mathrm{C} 4 \mathrm{Mim}][\mathrm{Cl}]<[\mathrm{C} 4 \mathrm{Mim}][\mathrm{Br}]<[\mathrm{C} 4 \mathrm{Mim}]\left[\mathrm{NO}_{3}\right]<$ [C4Mim] [I], with respect to their effectiveness in changing the location of a reflection spectral band; the peak position moves to the side of longer wavelength according to this order on salt addition.

The wavelength $\lambda_{\mathrm{M}}$ can be related to the cholesteric pitch $(P)$ by the de Vries equation, ${ }^{34} \lambda_{\mathrm{M}}=\tilde{n} \cdot P$, in a usual optical alignment of the normal incidence of light beam to the planar cholesteric sample. In this equation, $\tilde{n}$ is an average refractive index of the mesophase and it was evaluated using the formula $\tilde{n}=\left(2 n_{\|}+n \perp\right) / 3$ in this study. By the combined use of the data of refractive indices and that of selective reflection spectra, both measured in a temperature range of ca. $0-35^{\circ} \mathrm{C}$, a variation manner of the cholesteric pitch was estimated as a function of temperature for the respective liquid-crystalline systems composed of HPC and an aqueous imidazolium salt solvent. (In the refractometry measurement for this lyotropic series, irrespective of the salt used, the index $\tilde{n}$ decreased almost linearly with increasing temperature, for example, from 1.4499 at $5^{\circ} \mathrm{C}$ to 1.4400 at $35^{\circ} \mathrm{C}$ for a $62.5 \mathrm{wt} \%$ HPC liquid crystal containing $2.5 \times 10^{4} \mathrm{~mol}$ [C4Mim] [Br] per gram of solution. As exemplified hereby, the second place of decimals of the $\tilde{n}$ data was barely influenced by the temperature variation.) Figure 3 shows plots of the pitch vs temperature for $62.5 \mathrm{wt} \%$ HPC liquid crystals containing $2.5 \times 10^{4} \mathrm{~mol}[\mathrm{CnMim}][\mathrm{Br}]$ (Figure $3 \mathrm{a}$ ) or [C4Mim][X] (Figure $3 \mathrm{~b}$ ) per gram of solution. Essentially, the plot for any sample indicates a positive temperature dependence of $P$ to follow an approximately linear relation, at least in a comparatively lower-temperature side. However, there seems to exist a certain point at which the temperature dependence of the pitch changes from positive to negative. Actually, for example, such an inflection is observed at $15^{\circ} \mathrm{C}$ in the plots for [C2Mim][Br]- and [C4Mim][Cl]containing samples. This transition phenomenon may be ascribed to an embryonic phase separation on heating (see below), which is attended by the decrease in pitch due to the increase in equilibrium polymer concentration in the still cholesteric-ordered mesophase. ${ }^{12}$

With regard to the imidazolium salt-sort dependence of the cholesteric periodicity parameter, it is evident from the result shown in Figure 3 that both cation and anion constituents can affect the pitch, raising it according to the following orders: $[\mathrm{C} 2 \mathrm{Mim}]^{+}$ $<[\mathrm{C} 4 \mathrm{Mim}]^{+}<[\mathrm{C} 6 \mathrm{Mim}]^{+}$and $\mathrm{Cl}^{-}<\mathrm{Br}^{-}<\mathrm{NO}_{3}{ }^{-}<\mathrm{I}^{-}$. In supplementary circular dichroism measurements, all the salt-containing liquid crystals tested indicated a negative signal of circular reflectivity, implying that the cholesteric sense, that is, the handedness of the supramolecular helical arrangement remained right-handed, as it was so in the absence of any salt. Thus, the imidazolium salt addition was confirmed to alter simply the amplitude of $P$ as far as the solution retains the state of cholesteric monophase. 

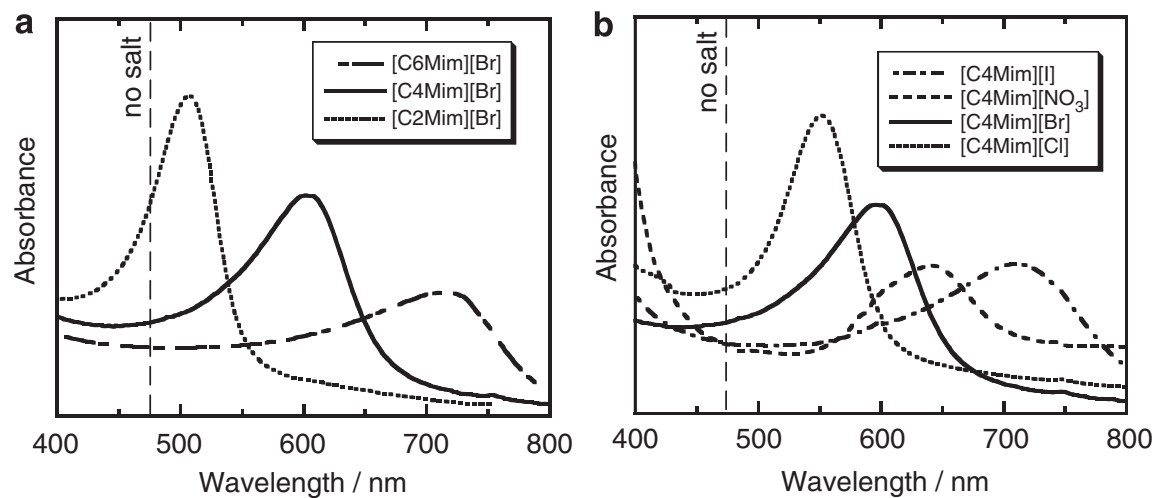

Figure 2 Selective light-reflection spectra at $10^{\circ} \mathrm{C}$ for imidazolium salt-containing two series of aqueous HPC liquid crystals, compared at polymer and salt concentrations of $62.5 \mathrm{wt} \%$ and $2.5 \times 10^{-4} \mathrm{~mol}$ per gram HPCaq, respectively. Additive salt: (a) $[\mathrm{CnMim}][\mathrm{Br}](n=2,4,6) ;(\mathbf{b})[\mathrm{C} 4 \mathrm{Mim}][\mathrm{X}]\left(\mathrm{X}=\mathrm{Cl}, \mathrm{Br}, \mathrm{NO} \mathrm{O}_{3}, \mathrm{I}\right)$. A vertical broken-line represents a position $(475 \mathrm{~nm})$ of $\lambda_{\mathrm{M}}$ for a salt-free sample of $62.5 \mathrm{wt} \%$ HPC.
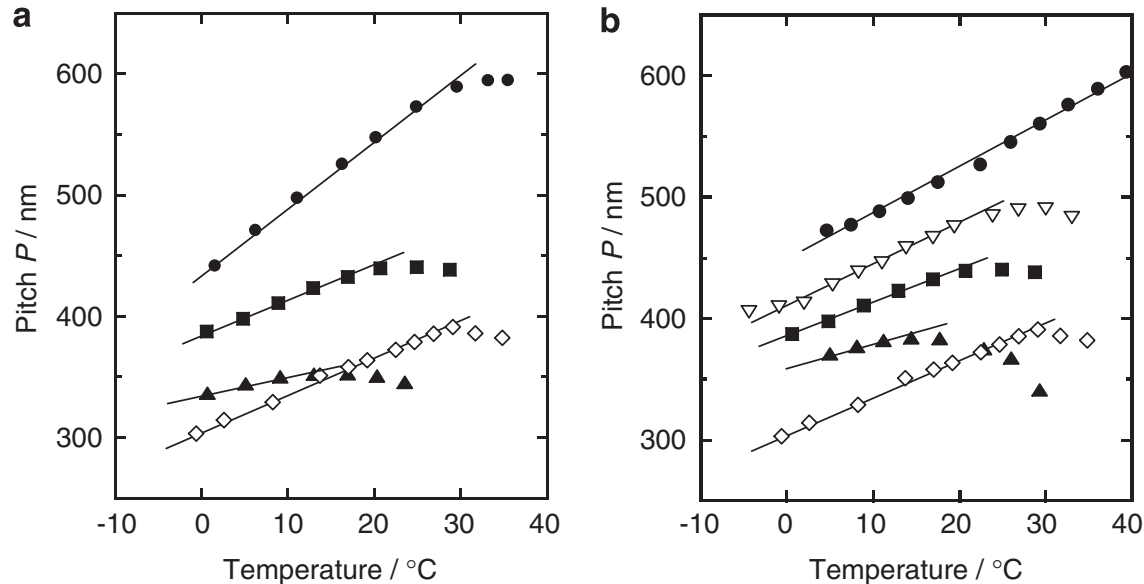

Figure 3 Temperature dependence of cholesteric pitch for HPC/imidazolium salt/water systems (HPC concentration, $62.5 \mathrm{wt} \%$; salt concentration, $2.5 \times 10^{-4} \mathrm{~mol}$ per gram HPCaq). (a) [CnMim] [Br]-containing series $(n=2,4,6)$; (b) [C4Mim] $\mathrm{X}$ ]-containing series $\left(X=\mathrm{Cl}, \mathrm{Br}, \mathrm{NO}_{3}, \mathrm{I}\right)$. Imidazolium cation in (a): $\bullet,[\mathrm{C} 6 \mathrm{Mim}]^{+} ; \mathbf{\square},[\mathrm{C} 4 \mathrm{Mim}]^{+} ; \boldsymbol{\Delta},[\mathrm{C} 2 \mathrm{Mim}]^{+} ; \diamond$, no salt. Anion in (b): $\bullet, \mathrm{I}^{-} ; \nabla, \mathrm{NO}_{3}^{-} ; \mathbf{\square}, \mathrm{Br}^{-} ; \mathbf{\Lambda}, \mathrm{Cl}^{-} ; \diamond$, no salt.

\section{LCST-type phase-separation behavior}

The solution system of HPC/water shows a unique, LCST-type phase diagram. ${ }^{5,11,12}$ A so-called cloud point $T_{c}$, at which the optical turbidity of such a binary mixture rises sharply on heating, is situated around $40^{\circ} \mathrm{C}$ with regard to isotropic aqueous HPC solutions, but it is rather lowered at higher HPC concentrations, leading to the mesophase formation. This phase-separation behavior of aqueous HPC solutions would also be affected by addition of imidazolium salts and the changing manner should depend on the ion species and concentration of the used one, as in the case of the previous HPC/water system containing conventional inorganic salts. ${ }^{13}$

$T_{\mathrm{c}}$-shifting effects of $[\mathrm{C} n \mathrm{Mim}][\mathrm{Br}]$ and of $[\mathrm{C} 4 \mathrm{Mim}][\mathrm{X}]$ actually observed for the present HPC/imidazolium salt/water system are illustrated in Figures $4 \mathrm{a}$ and $\mathrm{b}$, respectively, in which all $T_{\mathrm{c}}$ data were obtained at a $62.5 \mathrm{wt} \%$ HPC concentration eliciting a clear cholesteric ordering in the respective solutions and are plotted against the added salt concentration; however, $T_{\mathrm{c}}=29^{\circ} \mathrm{C}$ for a salt-free reference sample is marked by a dotted line. As can readily be inferred from the examples, the effectiveness of a given imidazolium salt in altering $T_{c}$, involving the directional sense and extent, would be determined by the arithmetic sum of the respective effects of its constituent ions.
First, we consider the addition effect of the $[\mathrm{C} n \mathrm{Mim}][\mathrm{Br}]$ series. As for bromine anion, it works as a weak depressant agent to the LCST of the HPC/water system, as has been established formerly, together with several other inorganic ions. ${ }^{13,14,16}$ From the plot of $T_{\mathrm{c}}$ for the $62.5 \mathrm{wt} \%$ HPC samples containing [C6Mim] [Br] in Figure $4 \mathrm{a}$, it can be declared that $[\mathrm{C} 6 \mathrm{Mim}]^{+}$acts as a $T_{\mathrm{c}}$ enhancer, at least at this HPC concentration; the elevating effect would have offset, or rather, surpassed the $T_{\mathrm{c}^{-}}$-depressing potency of $\mathrm{Br}^{-}$, resulting in a net increase in $T_{\mathcal{C}}$, which should be more pronounced with increasing salt concentration. The $T_{\mathrm{c}}$ vs salt concentration plot for the [C4Mim] $[\mathrm{Br}]$-containing samples in the same figure resembles that for the previously investigated $\mathrm{LiBr}$-containing samples of the corresponding HPC content, ${ }^{13}$ in the decreasing rate with salt concentration. Therefore, the $T_{\mathrm{c}^{-}}$-shifting ability of $[\mathrm{C} 4 \mathrm{Mim}]^{+}$may be comparable to that of $\mathrm{Li}^{+}$, which is a weak $T_{\mathrm{c}}$ depressor. More strictly, the $T_{\mathrm{c}}$-depressing potency of $\mathrm{Li}^{+}$is a little superior to that of $\mathrm{Br}^{-13}$ whereas that of $[\mathrm{C} 4 \mathrm{Mim}]^{+}$seems to be somewhat inferior to $\mathrm{Br}^{-}$at the $62.5 \mathrm{wt} \% \mathrm{HPC}$ concentration. The other organocation $[\mathrm{C} 2 \mathrm{Mim}]^{+}$with a still shorter $\mathrm{N}$-alkyl tail can be definitely assumed to depress the critical temperature of the concentrated HPC solution.

In Figure $4 \mathrm{~b}$, similar plots of $T_{\mathrm{c}}$ for $[\mathrm{C} 4 \mathrm{Mim}][\mathrm{I}]-$, [C4Mim] $\left[\mathrm{NO}_{3}\right]-$ and $[\mathrm{C} 4 \mathrm{Mim}][\mathrm{Cl}]$-added samples may be compared with that for the 

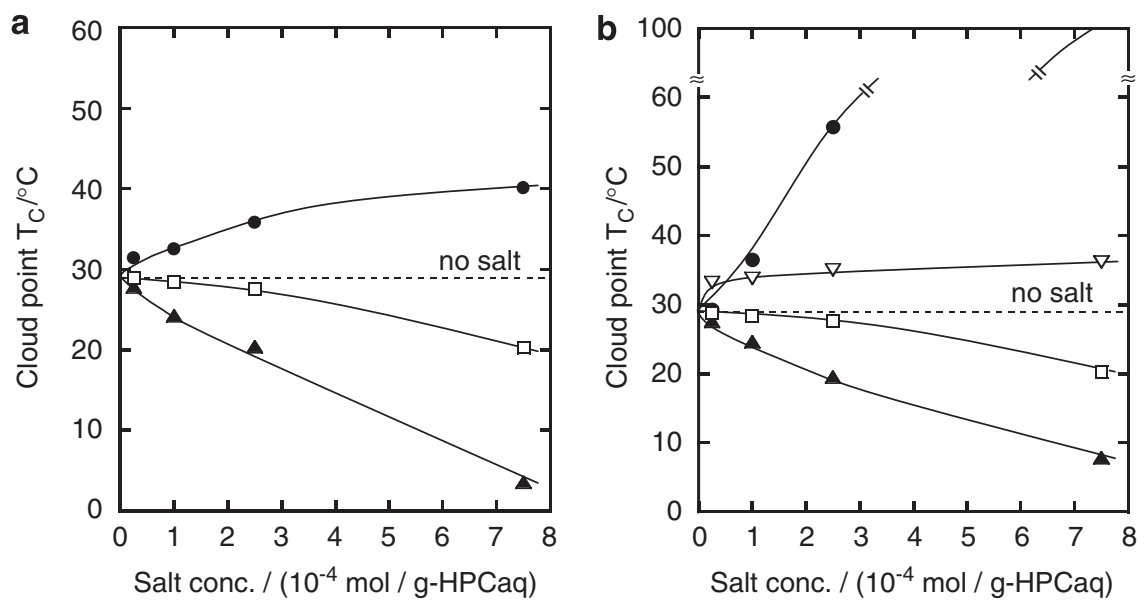

Figure 4 Cloud point $T_{\mathrm{c}}$ as a function of salt concentration for HPC/imidazolium salt/water systems, compared at a polymer concentration of $62.5 \mathrm{wt} \%$. (a) [CnMim][Br]-containing series ( $n=2,4,6)$; (b) [C4Mim][X]-containing series (X=Cl, Br, $\mathrm{NO}_{3}$, I). Imidazolium cation in (a): $\bullet,[\mathrm{C} 6 \mathrm{Mim}]^{+} ; \square,[\mathrm{C} 4 \mathrm{Mim}]^{+} ; \mathbf{\Delta}$, $[\mathrm{C} 2 \mathrm{Mim}]^{+} ;-. .--$, no salt. Anion in (b): $\bullet, \mathrm{I}^{-} ; \nabla, \mathrm{NO}_{3}^{-} ; \square, \mathrm{Br}^{-} ; \mathbf{\Lambda}, \mathrm{Cl}^{-} ;-. .--$, no salt.
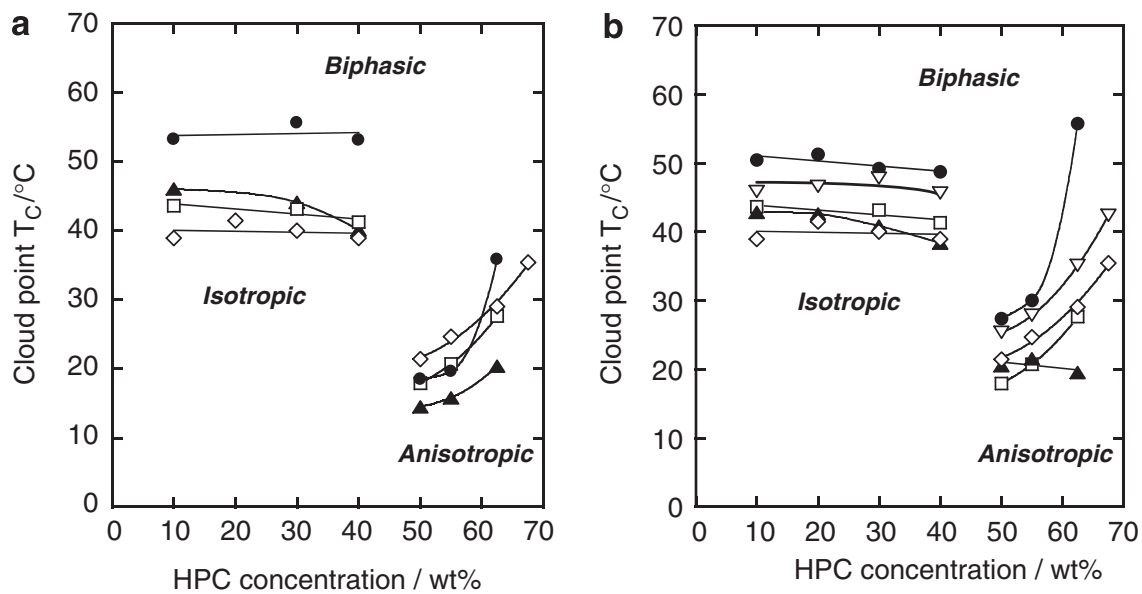

Figure 5 Cloud point vs polymer concentration, representing the respective phase diagrams of aqueous $\mathrm{HPC}$ solutions containing a salt of (a) [CnMim][Br] $(n=2,4,6)$ or (b) [C4Mim] $[\mathrm{X}]\left(X=\mathrm{Cl}, \mathrm{Br}, \mathrm{NO}_{3}, \mathrm{I}\right)$ at a concentration of $2.5 \times 10^{-4}$ mol per gram HPCaq. Imidazolium cation in (a): $\bullet$, [C6Mim] ${ }^{+}$; $\square$, $[\mathrm{C} 4 \mathrm{Mim}]^{+} ; \mathbf{\Delta},[\mathrm{C} 2 \mathrm{Mim}]^{+} ; \diamond$, no salt. Anion in (b): $\bullet, \mathrm{I}^{-} ; \nabla, \mathrm{NO}_{3}^{-} ; \square, \mathrm{Br}^{-} ; \mathbf{\Delta}, \mathrm{Cl}^{-} ; \diamond$, no salt.

addition of $[\mathrm{C} 4 \mathrm{Mim}][\mathrm{Br}]$. We can obviously recognize that the anions $\mathrm{I}^{-}$and $\mathrm{NO}_{3}{ }^{-}$elevate $T_{\mathrm{c}}$, and $\mathrm{Cl}^{-}$depresses it in the highly concentrated HPC/water system. Besides that, the $T_{\mathrm{c}}$ data for the $[\mathrm{C} 4 \mathrm{Mim}]\left[\mathrm{NO}_{3}\right]$ addition, generally higher than those for the $\mathrm{LiNO}_{3}$ addition, ${ }^{13}$ support the ranking of $[\mathrm{C} 4 \mathrm{Mim}]^{+}<\mathrm{Br}^{-}<\mathrm{Li}^{+}$regarding the $T_{\mathrm{c}}$-depressing potency.

Figure 5 compiles cloud point data plotted as a function of polymer concentration for aqueous HPC solutions containing an imidazolium salt of $[\mathrm{C} n \mathrm{Mim}][\mathrm{Br}]$ (in Figure $5 \mathrm{a}$ ) or [C4Mim] [X] (in Figure 5b) at a concentration of $2.5 \times 10^{-4}$ mol per gram HPCaq. With regard to the phase diagram of the binary system of HPC/water (non-salted), a detailed study has been accomplished by Fortin and Charlet. ${ }^{12}$ A point of great significance is in their discussion on a peculiarity that the LCST phase separation of the cholesteric liquid crystals takes place at lower temperatures than that of isotropic solutions. For the present HPC liquid-crystalline solutions in normal water, the data of $T_{c}$ at $\approx 23^{\circ} \mathrm{C}$ (at $50 \mathrm{wt} \%$ ), $25^{\circ} \mathrm{C}$ (at $55 \mathrm{wt} \%$ ), $29^{\circ} \mathrm{C}$ (at $62.5 \mathrm{wt} \%$ ) and $35.5^{\circ} \mathrm{C}$ (at $67.5 \mathrm{wt} \%$ ) were obtained, actually assuming rather smaller values compared with ca. $39^{\circ} \mathrm{C}$ for the isotropic samples of $\leqslant 40 \mathrm{wt} \%$
HPC (see rhombus-shaped plots in Figure 5). The less stability of the liquid-crystalline solutions on heating may be interpreted as being due to a conformational change of HPC accompanying the isotropic to anisotropic transition, namely, the polymer chains would display a more hydrophobic surface to the solvent in cholesteric mesophases than in isotropic solutions. ${ }^{12}$ However, this thought does not necessarily come into conflict with the possibility ${ }^{1,35}$ of a helical or twisted conformation in dilute solution of liquid-crystalline cellulosic polymers.

Plainly, the added imidazolium salts move the LCST-type phase boundary of the salt-free HPC solutions. An interesting finding in Figure 5 is that the phase-separation behavior mostly differs in the direction of the $T_{\mathrm{c}}$ shift between isotropic HPC solutions ( $\leqslant 40 \mathrm{wt} \%$ $\mathrm{HPC})$ and the liquid-crystalline ones ( $\geqslant 50 \mathrm{wt} \%)$, except for the $[\mathrm{C} 4 \mathrm{Mim}][\mathrm{I}]$ and $[\mathrm{C} 4 \mathrm{Mim}]\left[\mathrm{NO}_{3}\right]$ additions. Such a difference was never observed in the use of inorganic metallic salts as similar additives. ${ }^{13}$ In Figure $5 \mathrm{a}$, the $[\mathrm{C} n \mathrm{Mim}][\mathrm{Br}]$ series raises the original $T_{\mathrm{c}}$ in the isotropic region, particularly notable in the addition of a salt of a longer alkyl tail C6; $T_{c}$ values of $53^{\circ} \mathrm{C}$ (at $10 \mathrm{wt} \%$ ), $56^{\circ} \mathrm{C}$ (at 
$30 \mathrm{wt} \%$ ) and $53^{\circ} \mathrm{C}$ (at $40 \mathrm{wt} \%$ ) obtained for the [C6Mim][Br]containing system are higher, by as much as $15^{\circ} \mathrm{C}$, than the corresponding data $\left(\sim 39^{\circ} \mathrm{C}\right)$ for the salt-free samples. In contrast to this, the $\mathrm{C} n$-varying series is prone to depress the cloud point in the liquidcrystalline region; for example, at $55 \mathrm{wt} \% \mathrm{HPC},[\mathrm{C} 2 \mathrm{Mim}][\mathrm{Br}]$, $[\mathrm{C} 4 \mathrm{Mim}][\mathrm{Br}]$ and $[\mathrm{C} 6 \mathrm{Mim}][\mathrm{Br}]$ lowered the cloud point $\left(T_{\mathrm{c}}=\right.$ $24.7^{\circ} \mathrm{C}$ ) of the salt-free sample to $15.8^{\circ} \mathrm{C}, 20.7^{\circ} \mathrm{C}$ and $19.6^{\circ} \mathrm{C}$ in the respective additions at the same concentration of $2.5 \times 10^{-4} \mathrm{~mol}$ per gram HPCaq. The $T_{\mathrm{c}}$-elevating effect of [C6Mim] [Br] at $62.5 \mathrm{wt} \%$ HPC, stated above, may be taken to be a rather specific behavior, when the phase diagram of the salting system is overlooked in a full range of polymer concentration. It should be remarked here that the cholesteric pitches of the liquid-crystalline solutions of $\geqslant 50 \mathrm{wt} \%$ HPC were essentially increased by any of the $[\mathrm{C} n \mathrm{Mim}][\mathrm{Br}]$ additions. In the case in which conventional metallic salts were used for similar additives, some salts causing an increase in $P$ for the aqueous HPC liquid crystals exerted a $T_{\mathrm{c}}$-elevating effect on the same samples and even on the isotropic solutions as well, and other $P$-depressant salts were invariably $T_{\mathrm{c}}$ depressors in both isotropic and anisotropic HPC solutions.

From the $T_{\mathrm{c}}$ data shown in Figure $5 \mathrm{~b}$, we can specify an anion-sort dependence of the phase-separation behavior for the imidazolium salt-containing aqueous HPC solutions. Comparing the relative level of the phase boundary between the four salting systems, the positioning is found to follow an order of $\mathrm{Cl}^{-}<\mathrm{Br}^{-}<\mathrm{NO}_{3}{ }^{-}<\mathrm{I}^{-}$, although a small mismatch appears at polymer concentrations of 50 and $55 \mathrm{wt} \%$. This result would well reflect a general rule ${ }^{13}$ that iodide and nitrate ions behave as strong and moderate salting-in agents, respectively, which increase the solubility of HPC in water, whereas chlorine and bromine ions serve as strong and moderate salting-out agents, respectively, to depress $T_{\mathrm{c}}$ of the solution. However, the degree of dissociation of imidazolium chloride may be comparatively lower than the corresponding bromide, because the ionic bond energy of the former salt should be larger owing to the higher electronegativity of $\mathrm{Cl}$. This may be responsible for the small mismatch in the location of $T_{\mathcal{c}}$, observed in the anisotropic region of lower water content in Figure 5b.

\section{Further insight into salt addition effects}

Cholesteric structure. In this study, $\mathrm{N}$-alkyl-substituted imidazolium salts generally gave rise to an increase in the cholesteric pitch of aqueous HPC liquid crystals. Regarding the effectiveness of the respective salts, it followed the orders salt free $<[\mathrm{C} 2 \mathrm{Mim}][\mathrm{Br}]<$ $[\mathrm{C} 4 \mathrm{Mim}][\mathrm{Br}]<[\mathrm{C} 6 \mathrm{Mim}][\mathrm{Br}]$ and salt free $<[\mathrm{C} 4 \mathrm{Mim}][\mathrm{Cl}]<[\mathrm{C} 4 \mathrm{Mim}]$ $[\mathrm{Br}]<[\mathrm{C} 4 \mathrm{Mim}]\left[\mathrm{NO}_{3}\right]<[\mathrm{C} 4 \mathrm{Mim}][\mathrm{I}]$ (see Figure 3 ). The result for the $[\mathrm{C} 4 \mathrm{Mim}][\mathrm{X}]$ series is in accordance with a natural prediction from the chaotropic rank order ${ }^{13,14,16}$ of anions established formerly for the salted HPC/water system. However, it should be noted that even the addition of $[\mathrm{C} 4 \mathrm{Mim}][\mathrm{Cl}]$ resulted in an increase in the periodic parameter $P$, differing from the previous situation using alkali-metallic chlorides such as LiCl. Major alkali-metallic cations, as well as $\mathrm{Cl}^{-}$, were water-structure formers (that is, antichaotropic) and promoted a hydrophobic assemblage of nonpolar solute substances (alkyl side chains in HPC) to decrease the solubility in water. As to the $\mathrm{Cn}$-varying series of $[\mathrm{C} n \mathrm{Mim}][\mathrm{Br}]$, the observed manner of the $P$-increasing effect corresponds to the increase in chain length of the $\mathrm{N}$-alkyl substituent as a cation tail. However, it is rash to simply assume that the voluminous imidazolium salts of longer alkyl tail would further expand the distance between adjacent nematic layers in the cholesteric mesophase.

Figure 6 exemplifies selected data of WAXD intensity profiles measured for $62.5 \mathrm{wt} \%$ HPC aqueous solutions $\left(10^{\circ} \mathrm{C}\right)$ containing

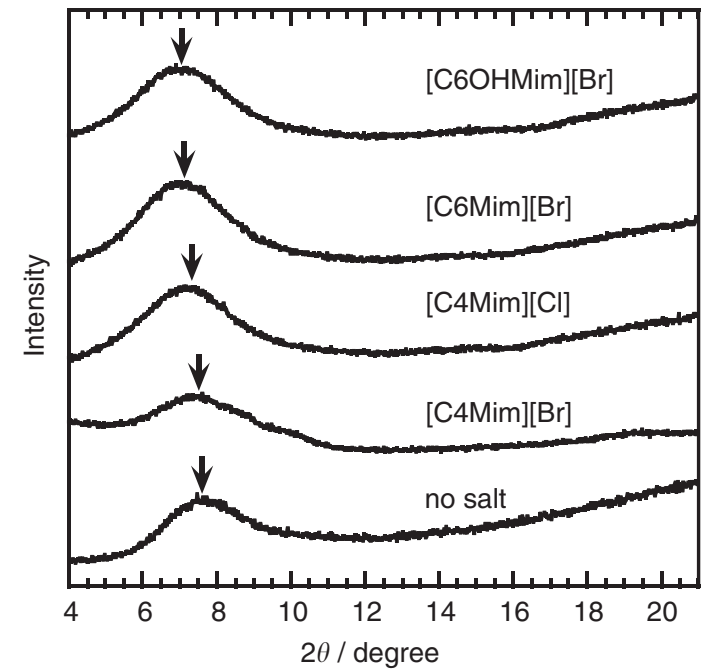

Figure 6 WAXD intensity profiles measured at $10^{\circ} \mathrm{C}$ for $62.5 \mathrm{wt} \%$ HPC liquid crystals in water containing various imidazolium salts at $2.5 \times 10^{-4} \mathrm{~mol}$ per gram HPCaq.

Table 1 Cholesteric pitch $(P)$, distance between adjacent nematic layers $(d)$, twist angle $(\varphi)$ and twisting power $\left(360^{\circ} / P\right)$, estimated at $10^{\circ} \mathrm{C}$ for $62.5 \mathrm{wt} \% \mathrm{HPC}$ solutions containing various imidazolium salts at a concentration of $2.5 \times 10^{-4} \mathrm{~mol}$ per gram HPCaq

\begin{tabular}{|c|c|c|c|c|}
\hline Additive salt & $P(n m)$ & $\mathrm{d}(n m)$ & $\varphi$ (degree) & $\begin{array}{c}\text { Twisting power, } \\
360^{\circ} \mathrm{P}\left(\text { degree } \mathrm{nm}^{-1}\right)\end{array}$ \\
\hline None & 337 & 1.17 & 1.25 & 1.07 \\
\hline [C4Mim] $[\mathrm{Cl}]$ & 379 & 1.22 & 1.16 & 0.95 \\
\hline [C4Mim] $[\mathrm{Br}]$ & 415 & 1.18 & 1.02 & 0.86 \\
\hline$[\mathrm{C} 4 \mathrm{Mim}]\left[\mathrm{NO}_{3}\right]$ & 443 & 1.24 & 1.01 & 0.81 \\
\hline [C4Mim][I] & 488 & 1.16 & 0.85 & 0.73 \\
\hline [C2Mim] $[\mathrm{Br}]$ & 350 & 1.23 & 1.27 & 1.03 \\
\hline [C2OHMim][Br] & 347 & 1.23 & 1.28 & 1.04 \\
\hline [C6Mim] $[\mathrm{Br}]$ & 491 & 1.26 & 0.92 & 0.73 \\
\hline [C6OHMim][Br] & 418 & 1.27 & 1.09 & 0.86 \\
\hline [s-C4Mim][Br] & 415 & 1.16 & 1.01 & 0.87 \\
\hline [i-C4Mim][Br] & 388 & 1.14 & 1.06 & 0.93 \\
\hline$[\mathrm{MimC} 4 \mathrm{Mim}][\mathrm{Br}]_{2}$ & 410 & 1.12 & 0.98 & 0.88 \\
\hline
\end{tabular}

Abbreviation: HPC, hydroxypropyl cellulose.

various imidazolium salts. All intensity curves showed only one diffraction peak at an angular position of $2 \theta=7-8^{\circ}$, except for a diffuse scattering halo centering $2 \theta \approx 22^{\circ}$. Therefore, the short-range ordering of less than a few nanometers in the cholesteric mesophase of HPC would be analyzable in terms of a pseudohexagonal packing of the molecular chains, ${ }^{36}$ whereupon the normal distance $(d)$ between the nematic layers stacking in the mesophase may be directly calculated from the low-angle peak. The result of the calculation is shown in Table 1 , where the cholesteric twist angle, $\varphi$, defined as an azimuth difference between adjacent nematic layers, is also estimated from the relation $\varphi=360^{\circ}(d / P)$ using $d$ and $P$ data. Evidently, the addition of imidazolium salts gave rise to only a slight expansion of the layer spacing. When comparing $[\mathrm{C} 4 \mathrm{Mim}][\mathrm{X}]$-added samples, the systematic 

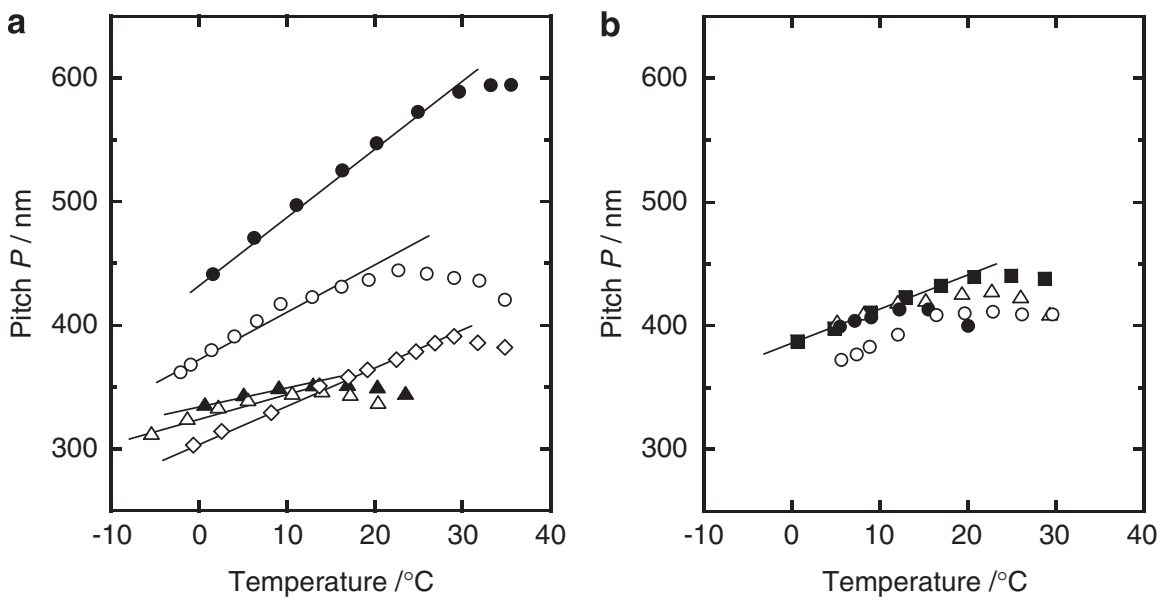

Figure 7 Cholesteric pitch vs temperature plots for HPC/imidazolium salt/water systems (HPC concentration, 62.5 wt $\%$; salt concentration, $2.5 \times 10^{-4}$ mol per gram HPCaq). Salt in (a): $\bullet$, [C6Mim][Br]; $O$, [C6OHMim][Br]; $\mathbf{\Delta},[\mathrm{C} 2 \mathrm{Mim}][\mathrm{Br}] ; \triangle$, [C2OHMim][Br]; $\diamond$, no salt. Salt in (b): $\mathbf{\square}$, [C4Mim][Br]; $\triangle$, $[s-\mathrm{C} 4 \mathrm{Mim}][\mathrm{Br}] ;$ O , [i-C4Mim][Br]; •, [MimC4Mim] $[\mathrm{Br}]_{2}$.

decline in cholesteric twisting power $\left(\propto P^{-1}\right)$ with an increase in chaotropic strength of $\mathrm{X}^{-}$is found to be principally due to the decreasing twist angle $\varphi$. Even in the $[\mathrm{CnMim}][\mathrm{Br}]$-added series, it is the decrease in $\varphi$ rather than the increase in $d$ that substantially contributes to the rise in $P$ with increasing carbon number.

The data of $d=1.17 \mathrm{~nm}$ (for salt-free sample) and $1.26 \mathrm{~nm}$ (for [C6Mim][Br]-added one) can be converted to $L=1.35$ and $1.45 \mathrm{~nm}$, respectively, by $L=d / \cos 30^{\circ}$, where $L$ denotes the diameter of the respectively solvated HPC chains approximated to a cylinder. $L=1.35 \mathrm{~nm}$ is a little larger than molecular diameter $a=1.16 \mathrm{~nm}$, which was calculated for a dry HPC (density, $\left.\rho \approx 1.20 \mathrm{~g} \mathrm{~cm}^{-3}\right)^{5}$ by a solid geometrical relation assuming the chain segment to be cylindrical in shape. (By doing this, the diameter $a$ can be calculated by the geometrical relation $a=\left[4 M_{\mathrm{u}} /\left(\pi N_{\mathrm{A}} \rho l_{\mathrm{u}}\right)\right]^{1 / 2}$, where $M_{\mathrm{u}}\left(396.7 \mathrm{~g} \mathrm{~mol}^{-1}\right)$ and $l_{\mathrm{u}}(0.52 \mathrm{~nm})$ are the molecular weight and length of a repeating unit, respectively, of HPC $(\mathrm{MS}=4.04) ; \rho$ is the density $(\approx 1.20 \mathrm{~g}$ $\left.\mathrm{cm}^{-3}\right)^{5}$ of HPC and $N_{\mathrm{A}}$ is Avogadro's number.) The difference of $<0.2 \mathrm{~nm}$ is reasonable by taking into account the surrounding water molecules. The other estimate $L=1.45 \mathrm{~nm}$ also shows only a little increase $(\sim 0.3 \mathrm{~nm})$ relative to the $a$ value, the increment being comparable with the diameter $(0.3-0.35 \mathrm{~nm})$ of an annular imidazolio group. Thus, from these dimensional comparisons based on WAXD measurements, it can be concluded that the $[\mathrm{Cn} \mathrm{Mim}][\mathrm{X}]$ additives never seriously affect the hexagonally close-packed structure of HPC molecules in the aqueous mesophase, at least with regard to distances. However, in view of the systematic dependence of the cholesteric twist angle $\varphi$ on the carbon number of $[\mathrm{C} n \mathrm{Mim}]^{+}$, a part of the voluminous organo-entity, probably the $N$-alkyl tail, may be allowed to intrude into the side-chain domain of HPC. Such a perturbation should be a factor involved in altering an asymmetric form of the cellulose derivative molecule as a whole.

As has been described in a recent study, ${ }^{37}$ some imidazolium ionic liquids (even the ones with a relatively shorter alkyl chain of $n<10$ ) can show a cationic surfactant-like behavior in aqueous solutions; however, if the heteropolar bond of the ion pair is too strong, that is, the dissociation is restrained, the surface activity is weak. The salt [C6Mim] $[\mathrm{Br}]$ seems to indicate, rather significantly, such a surfactant nature in the present ternary system. In the cholesteric mesophase (62.5 wt\% HPC) containing this salt, for example, the hexyl tail of $\left.{ }^{\mathrm{C} 6 \mathrm{Mim}}\right]^{+}$would merge into the hydrophobic side-chain region of HPC, whereby the polymer molecule is possibly more stable electro- statically because of the newly evolved ionic surface. Figure 7a shows cholesteric pitch vs temperature plots obtained for [C6OHMim] [Br]and [C2OHMim] $[\mathrm{Br}]$-added $62.5 \mathrm{wt} \% \mathrm{HPC} /$ water liquid crystals, to compare them with the respective data for the corresponding [C6Mim] $[\mathrm{Br}]-$ and $[\mathrm{C} 2 \mathrm{Mim}][\mathrm{Br}]$-containing samples. It can be seen that the attachment of an $\mathrm{OH}$ group at the hexyl end of [C6Mim $]^{+}$ seriously represses such a $P$-increasing action as that exercised by [C6Mim] $[\mathrm{Br}]$, most probably as a result of degeneration of the surface activity to stabilize HPC molecules electrostatistically. While using

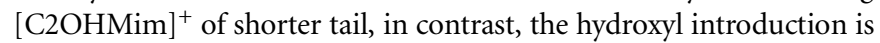
found to be almost ineffective in altering the $P$ vs temperature behavior of the [C2Mim] $[\mathrm{Br}]$-added sample, reflecting the originally feeble surface-active agency of $[\mathrm{C} 2 \mathrm{Mim}][\mathrm{Br}]$. With regard to the spatial short-range order in the cholesteric structure, these modifications of $[\mathrm{C} n \mathrm{Mim}]^{+}(n=2,6)$ using hydroxyl never affected the layer spacing $d$ in the mesophase concerned, and only the hydroxylation of the hexyl end increased the twist angle $\varphi$ (see Table 1).

In Figure $7 \mathrm{~b}, P$ vs temperature data are compared between [C4Mim] $[\mathrm{Br}]-, \quad[s-\mathrm{C} 4 \mathrm{Mim}][\mathrm{Br}]-, \quad[i-\mathrm{C} 4 \mathrm{Mim}][\mathrm{Br}]-$ and $[\mathrm{MimC} 4-$ $\mathrm{Mim}][\mathrm{Br}]_{2}$-added samples, all salts having a butyl chain as their hydrophobic part. We find no remarkable difference in location between the plots for the four samples, although the [i-C4Mim] $[\mathrm{Br}]$-added sample yielded somewhat lower $P$-values in the temperature range explored. The amphiphilicity of $[\mathrm{C} 4 \mathrm{Mim}]^{+}$, which can be reasonably taken as being intermediate between $[\mathrm{C} 2 \mathrm{Mim}]^{+}$and $[\mathrm{C} 6 \mathrm{Mim}]^{+}$, seems to be only slightly regressed by branching of the butyl chain. The less $P$-shifting effect of the twin-type cation $[\mathrm{MimC} 4 \mathrm{Mim}]^{2+}$ is not well interpretable at present, but it may be plausible to assume that only the central alkyl part sinks in the sidechain domain of HPC. In this case, the gain of electrostatic stability (to elevate $P$ ) due to the duplicated surface-active agency would be offset by an increase in the antichaotropic effect of $\mathrm{Br}^{-}$(to reduce $P$ ) due to twice the amount. WAXD measurements indicated again that any of the structural modifications of $[\mathrm{C} 4 \mathrm{Mim}]^{+}$were an inert factor unaffecting the layer spacing in the HPC mesophase concerned, as can be seen from comparison of the corresponding $d$ data in Table 1.

LCST behavior. The imidazolium salt-addition effect on the LCST of aqueous HPC solutions, shown in Figure 5, seems to be yet more intricate, especially in a $\mathrm{C} n$-dependent changing manner. As a trend found in perspective, the cloud point $T_{c}$ was shifted by addition of 
$[\mathrm{C} n \mathrm{Mim}][\mathrm{X}]$, upward at lower HPC concentrations (isotropic region) and downward at higher ones (anisotropic region). This result may also be explained principally in terms of the surfactant-like character of the organo-ionic salts derived from the amphiphilic structure. In the interpretation, it should be taken into account that surface-active agents can self-aggregate in water, as well as incorporate with the third organic component in the aqueous solution.

In the isotropic aqueous HPC solutions ( $\leqslant 40 \mathrm{wt} \%)$, [CnMim][X] salts would be well-ionized and interact, more or less, with the hydrophobic part of the HPC molecule by the alkyl intrusion of $[\mathrm{CnMim}]^{+}$, so that the polymer is stably solubilized in water. (There have been some interesting studies with regard to the interaction (adsorption or binding) of popular ionic surfactants with HPC molecules in aqueous solutions. See, for examples Hormnirun et al. ${ }^{38}$ and Drummond et al..$^{39}$ ). This should raise the LCST, compared with the salt-free situation. A longer alkyl chain of $[\mathrm{C} n \mathrm{Mim}]^{+}$may be favorable for the effective action. A result supporting this view is given in Figure 8, where the phase diagrams of differently salted HPC solutions are compared (a) between the use of $[\mathrm{C} 6 \mathrm{Mim}][\mathrm{Br}]$ and that of $[\mathrm{C} 6 \mathrm{OHMim}][\mathrm{Br}]$ and (b) between the use of $[\mathrm{C} 2 \mathrm{Mim}][\mathrm{Br}]$ and that of [C2OHMim] $[\mathrm{Br}]$. We find that, when the original amphiphilic nature of the added imidazolium salts is quenched by $\mathrm{OH}$ attachment, a lowering of $T_{\mathrm{c}}$ takes place in the isotropic region and the extent is more striking in the hydroxylation of the C6-tail end.

In the anisotropic samples of $\geqslant 50 \mathrm{wt} \%$, the added imidazolium salts would be condensed between HPC molecules that are oriented in the nematic layers constituting the cholesteric mesophase. Thereupon, the degree of ionic dissociation of the salt would be generally lowered, and, instead, a self-association nature of the salt to form an aggregate could be pronounced; ${ }^{37}$ then, the aggregate may be stabilized by water molecules as a bridge being able to form hydrogen bond with the anionic moieties of two salts close to each other. ${ }^{40}$ This implies a decrease in the number of the water ingredient to hydrate the hydrophobic surface of mesogenic HPC molecules, relative to the hydration condition in the corresponding HPC/water composition free of any salt. The ascendant salting-out and dehydration for the solute polymer should accelerate the LCST phase-separation of the aqueous system on heating. In Figure 5a (anisotropic region therein), nevertheless, it is still inscrutable to observe a comparatively greater extent of $T_{\mathrm{c}}$ depression when [C2Mim] ${ }^{+}$of a shorter $N$-alkyl tail was used as the imidazolium constituent to be added. As has been stated in the preceding section 'Cholesteric structure', imidazolium cations of longer alkyl tail, such as $[\mathrm{C} 6 \mathrm{Mim}]^{+}$, can also stabilize the individual solute HPC molecule by encapsulating the hydrophobic domain. This effect of electrostatic stability (leading to $T_{\mathrm{c}}$ elevation) would be in competition with the above-mentioned effect of salting-out and dehydration (leading to $T_{\mathrm{c}}$ depression) in the [C6Mim] $[\mathrm{Br}]$-containing anisotropic samples, and, at $62.5 \mathrm{wt} \% \mathrm{HPC}$, the former contribution seems to be superior to the other. Thereafter, the hydroxyl modification of the C6-tail end of the imidazolium salt should reduce the electrostatic stability and make a new balance of the $T_{\mathrm{c}}$-elevating and -depressing contributions. We can see the supporting evidence, a positional change of $T_{\mathrm{c}}$ after $\mathrm{OH}$ introduction, again in Figure $8 \mathrm{a}$ (anisotropic region therein). With regard to $T_{\mathfrak{c}}$ data for the [C2OHMim] $[\mathrm{Br}]$-containing system (Figure $8 \mathrm{~b}$ ), we found only a slight elevation at the respective anisotropic HPC concentrations, relative to the corresponding data for the $[\mathrm{C} 2 \mathrm{Mim}][\mathrm{Br}]$ addition.

In the case in which imidazolium iodides were used as the additive, we observed an exceptionally higher $T_{\mathrm{c}}$ behavior even in the anisotropic region of the phase diagram (see Figure $5 \mathrm{~b}$ ). This observation can be ascribed directly to the stronger chaotropicity of isolated $\mathrm{I}^{-}$acting as a hydrophobic-bond disrupting agent to enhance the solubility of HPC in water. Presumably, the effective exercise of the chaotropicity of $\mathrm{I}^{-}$is owing to a higher dissociation character of $[\mathrm{C} n \mathrm{Mim}][\mathrm{I}]$; the electronegativity of iodine is comparatively lower, and, therefore, the ionic bond energy of the salt should also be weaker than those of the corresponding bromide and chloride.

\section{Preliminary examination of electro-optical behavior}

A result of electro-optical observations with a handy-type cell is illustrated in Figure 9 for a cholesteric liquid-crystalline HPC/ $[\mathrm{C} 4 \mathrm{Mim}][\mathrm{Br}] /$ water system (polymer concentration, $62.5 \mathrm{wt} \%$; salt concentration, $2.5 \times 10^{-4}$ mol per gram HPCaq). The cell was made up of slide glasses, two carbon plates as a pair of inert electrodes and spacers, and a supplementary Teflon spacer. The sample was sealed in a layer of solution between the parallel slide glasses spaced by the carbon electrodes $500 \mu \mathrm{m}$ thick. In this electrification experiment at $20^{\circ} \mathrm{C}$, the potential difference applied between the twinning electrodes was $2.5 \mathrm{~V}$, their sectional planes being apart at a distance of $8 \mathrm{~mm}$ (that is, the electric field $E=3.13 \mathrm{~V} \mathrm{~cm}^{-1}$ ).
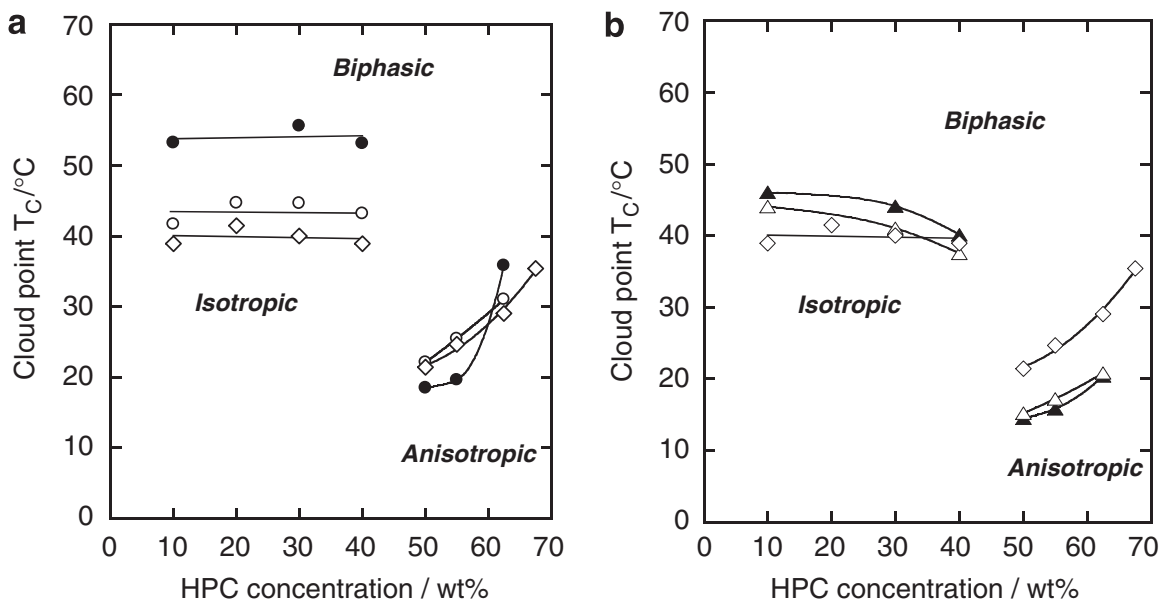

Figure 8 Cloud point vs polymer concentration plots, comparing the phase diagrams of aqueous HPC solutions each containing one of the following imidazolium bromides at a concentration of $2.5 \times 10^{-4} \mathrm{~mol}$ per gram HPCaq. Salt in (a): $\bullet$, [C6Mim][Br]; $\bigcirc$, [C6OHMim][Br]; $\diamond$, no salt (for reference). Salt in (b): $\boldsymbol{\Delta}$, [C2Mim] [Br]; $\triangle$, [C2OHMim][Br]; $\diamond$, no salt (for reference). 
a

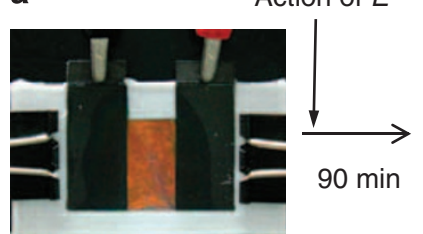

b

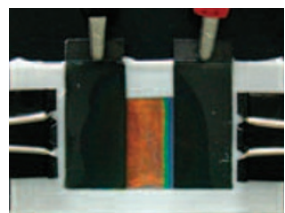

c

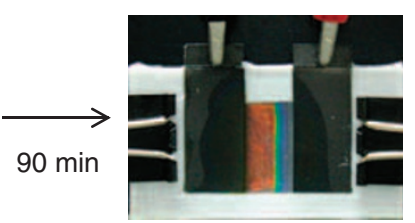

Figure 9 Variation in cholesteric reflection color of an $\mathrm{HPC} /[\mathrm{C} 4 \mathrm{Mim}][\mathrm{Br}] /$ water system at $20^{\circ} \mathrm{C}$ (HPC concentration, $62.5 \mathrm{wt} \%$; salt concentration, $2.5 \times 10^{-4} \mathrm{~mol}$ per gram HPCaq), followed with an elapse of time after electrification. (a) Initial quiescent state; (b) after $90 \mathrm{~min}$; (c) after $180 \mathrm{~min}$. The liquid-crystalline sample was loaded in a cell of horizontal type with a pair of carbon electrodes and subjected to the action of an electric field of $E=2.5 \mathrm{~V} / 8 \mathrm{~mm}$.

In the initial stage free of the electric field, the sample was uniformly colored reddish orange (Figure 9a). However, the voltage application to the sample gave rise to a definite variation in the reflection color. In about 90 min after imposing the electric stimulation, the cholesteric solution exhibited reddish and bluish hues in the vicinity of the positive and negative plates, respectively, as shown in Figure 9b. When another $90 \mathrm{~min}$ passed (Figure $9 \mathrm{c}$ ), the reflective colors of the sample ranged from deep red on the positive side through to yellow green in the central part to blue and violet on the negative side, and an increase in haziness was also perceived in close proximity to the negative plate. This finding of dynamic change in the coloration and optical clarity indicates formation of a magnitude gradient referring both to the cholesteric pitch and to the critical temperature of phase separation in the imidazolium salt-added HPC liquid-crystal, possibly coming from an uneven ionic distribution generated by the external electric field.

Phenomenologically, the present result is similar to that observed in the previous experiment using conventional inorganic salts. ${ }^{17}$ However, there may be a certain difference between the two cases, in the process generating the disparity in cation/anion distribution. In the previous case, the electrical stimulation allows ion particles to directly migrate and localize in the lyotropic system, as the added salt would have already been completely ionized. In the present system, the applied electric field would induce or promote dissociation of the added imidazolium salt in the first place. After that, the migration of the bulky $N$-alkyl-substituted imidazolium cation would be slower in progress, but, instead, some change in the orientational allocation may be possible; that is, the proportion of $[\mathrm{CnMim}]^{+}$oriented perpendicular to the nematic layers would fall into a decline, followed by prevalence of the preferred orientation parallel to the layers. This spatial perturbation should reduce the contribution of the organocation to stabilize solute HPC molecules electrostatically, resulting in a decrease in the cholesteric pitch (principally in the side of the negative pole). Virtually, however, it should be determined by the total balance with other effects including the chaotropicity of the counter anion that fluctuated differently from the cation. In this connection, the annular imidazolio moiety itself might act essentially as an antichaotropic ion to this aqueous system, the nature being latent unless the surface activity in the $N$-alkyl-substituted form is extinguished by such an electric force. Further characterization of the electro-optical behavior is a topic to be reported in our subsequent paper.

\section{CONCLUSION}

The addition effects of $[\mathrm{CnMim}][\mathrm{X}]$ on the mesophase structure and LCST-type phase-separation behavior, and the ensuing optical properties of concentrated aqueous HPC solutions, were investigated mainly by spectrophotometry. With regard to the anion-sort dependence of the cholesteric pitch $(P)$ and cloud point $\left(T_{\mathrm{c}}\right)$, it was clearly shown that both $P$ and $T_{\mathrm{c}}$ shift upward according to the chaotropic strength of $\mathrm{X}^{-}$, that is, in a manner satisfying the order of $\mathrm{Cl}^{-}<\mathrm{Br}^{-}$ $<\mathrm{NO}_{3}{ }^{-}<\mathrm{I}^{-}$, if the added imidazolium salt is well dissociated. The organocations generally tended to raise $P$ relative to the nonionic reference, the effectiveness being pronounced in the order of the chain length of the $\mathrm{N}$-alkylsubstituent, that is, $[\mathrm{C} 2 \mathrm{Mim}]^{+}<{\text {[C4Mim }]^{+}}^{+}$ $<[\mathrm{C} 6 \mathrm{Mim}]^{+}$. In spite of the voluminous structure, any of the added salts caused less expansion of the nematic layer spacing in the cholesteric mesophase, as indicated by WAXD measurements; only the cholesteric twist angle was affected noticeably by the additions. In a possible interpretation, it was assumed that $\mathrm{N}$-alkyl substituents could merge into the hydrophobic side-chain region of each individual HPC molecule, because of the surface-active agency of amphiphilic $[\mathrm{CnMim}]^{+}$, which should be prominent with an increase in the carbon number. This view was supported by a comparative $P$ measurement, with the specific imidazolium additives having a hydrophilic hydroxyl group at the $N$-alkyl chain end.

With regard to the effect of imidazolium salts on LCST behavior, the habitual surfactant-like action of the organocations to HPC molecules properly works as a $T_{\mathrm{c}}$-elevating factor, because of the gain of electrostatic stability for the solute polymer in aqueous solutions. The $T_{\mathrm{c}}$ data observed in the isotropic region of the phase diagrams for the $[\mathrm{CnMim}][\mathrm{Br}]$-added systems (Figure $5 \mathrm{a}$ ), the value elevating with increasing $N$-alkyl chain length, may be interpreted as due to predominance of this stabilization factor. In the anisotropic condensed HPC solutions, however, the self-aggregation of imidazolium salts may be partly possible in the nondissociated form, but with accompanying water molecules. This should operate as a $T_{\mathrm{c}}$-depressing factor, heightening the hydrophobic character of the solute HPC. Thus, the imidazolium additive-containing aqueous HPC liquidcrystalline system is, in general, equilibrated under the multi-influences comprising the mutually competitive electrostatic and hydrophobic factors and the additional chaotropic effect of isolated anions. The cloud point is determined by the prominence of any of the plural factors and variable depending on the combination of the cation/ anion pair used.

Finally, it was preliminarily shown that the imidazolium salts can also be a mediator to dynamically control the cholesteric coloration and optical turbidity of this lyotropic system under the action of a weak electric field. The observed electro-optical phenomenon may be attributed decisively to the generation of a disproportionate cation/ anion dislocation; but it should be noted as a matter of significance that the electrification would promote dissociation of the ion pair and, as well, re-orientation of the organocation initially stabilizing solute HPC.

\section{ACKNOWLEDGEMENTS}

We acknowledge Professor M Watanabe of Yokohama National University for his useful discussion about the preparation of different imizadolium salts. This 
work was partially financed by a Grant-in-Aid for Scientific Research (A) (No. 20248019 to YN) from the Japan Society for the Promotion of Science.

1 Guo, J.- X. \& Gray, D. G. in Cellulosic Polymers, Blends and Composites (ed. Gilbert, R.D.) Ch. 2 (Carl Hanser, Munich and New York, 1994).

2 Gray, D. G. \& Harkness, B. R. in Liquid Crystalline and Mesomorphic Polymers (eds Shibaev, V.P. \& Lam, L.) 298 (Springer, New York, 1994).

3 Zugenmaier, P. in Cellulosic Polymers, Blends and Composites (ed. Gilbert, R.D.) Ch. 4 (Carl Hanser, Munich and New York, 1994).

4 Zugenmaier, P. in Handbook of Liquid Crystals (eds Demus, D., Goodby, J., Gray, G.W., Spiess, H.-W. \& Vill, V.) Vol. 3, Ch. 9 (Wiley, Weinheim, 1998).

5 Werbowyj, R. S. \& Gray, D. G. Ordered phase formation in concentrated hydroxypropyl cellulose solutions. Macromolecules 13, 69-73 (1980).

6 Gray, D. G. Liquid crystalline cellulose derivatives. J. Appl. Polym. Sci. Appl. Polym. Symp. 37, 179-192 (1983).

7 Gilbert, R. D. \& Patton, P. A. Liquid crystal formation in cellulose and cellulose derivatives. Prog. Polym. Sci. 9, 115-131 (1983)

8 Gray, D. G. Chemical characteristics of cellulosic liquid crystals. Faraday Discuss. Chem. Soc. 79, 257-264 (1985).

9 Shimamura, K., White, J. A. \& Fellers, J. F. Hydroxypropylcellulose, a thermotropic liquid crystal: characteristics and structure development in continuous extrusion and melt spinning. J. Appl. Polym. Sci. 26, 2165-2180 (1981).

10 Werbowyj, R. S. \& Gray, D. G. Liquid crystalline structure in aqueous hydroxypropyl cellulose solutions. Mol. Cryst. Liq. Cryst. (Lett.) 34, 97-103 (1976).

$11 \mathrm{Klug}$, E. D. Some properties of water-soluble hydroxyalkyl celluloses and their derivatives. J. Polym. Sci. Part C 36, 491-508 (1971).

12 Fortin, S. \& Charlet, G. Phase diagram of aqueous solutions of (hydroxypropyl)cellulose. Macromolecules 22, 2286-2292 (1989).

13 Nishio, Y., Chiba, R., Miyashita, Y., Oshima, K., Miyajima, T., Kimura, N. \& Suzuki, H. Salt addition effects on mesophase structure and optical properties of aqueous hydroxypropyl cellulose solutions. Polym. J. 34, 149-157 (2002).

14 Nishio, Y. \& Chiba, R. Structural characteristics and novel functionalization of liquidcrystalline polysaccharides and cholesterol derivatives. Ekisho 7, 218-227 (2003).

15 Nishio, Y. Material functionalization of cellulose and related polysaccharides via diverse microcompositions. Adv. Polym. Sci. 205, 97-151 (2006).

16 Chiba, R., Nishio, Y., Sato, Y., Ohtaki, M. \& Miyashita, Y. Preparation of cholesteric (hydroxypropyl)cellulose/polymer networks and ion-mediated control of their optical properties. Biomacromolecules 7, 3076-3082 (2006).

17 Chiba, R., Nishio, Y. \& Miyashita, Y. Electrooptical behavior of liquid-crystalline (hydroxypropyl)cellulose/inorganic salt aqueous solutions. Macromolecules 36, $1706-1712$ (2003).

18 Nishio, Y., Kai, T., Kimura, N., Oshima, K. \& Suzuki, H. Controlling the selective light reflection of a cholesteric liquid crystal of (hydroxypropyl)cellulose by electrical stimulation. Macromolecules 31, 2384-2386 (1998).

19 lonic Liquids in Synthesis (eds Wasserscheid, P. \& Welton, T.) (Wiley-VCH: Weinheim 2007).

20 Kubisa, P. Application of ionic liquids as solvents for polymerization processes. Prog. Polym. Sci. 29, 3-12 (2004).
21 Zhao, H. \& Malhotra, S. V. Applications of ionic liquids in organic synthesis. Aldrichim. Acta 35, 75-83 (2002).

22 Electrochemical Aspects of Ionic Liquids (ed. Ohno, H.) (John Wiley \& Sons, Inc.: Hoboken, NJ 2005).

23 El Seoud, O. A., Koschella, A., Fidale, L. C., Dorn, S. \& Heinze, T. Applications of ionic liquids in carbohydrate chemistry: a window of opportunities. Biomacromolecules $\mathbf{8}$, 2629-2647 (2007)

24 Swatloski, R. P., Spear, S. K., Holbrey, J. D. \& Rogers, R. D. Dissolution of cellulose with ionic liquids. J. Am. Chem. Soc. 124, 4974-4975 (2002).

25 Heinze, T., Schwikal, K. \& Barthel, S. Ionic liquids as reaction medium in cellulose functionalization. Macromol. Biosci. 5, 520-525 (2005).

26 Zhang, H., Wu, J., Zhang, J. \& He, J. 1-Allyl-3-methylimidazolium chloride room temperature ionic liquid: a new and powerful nonderivatizing solvent for cellulose. Macromolecules 38, 8272-8277 (2005).

27 Fukaya, Y., Sugimoto, A. \& Ohno, H. Superior solubility of polysaccharides in low viscosity, polar, and halogen-free 1,3-dialkylimidazolium formates. Biomacromolecules 7, 3295-3297 (2006)

28 Fukaya, Y., Hayashi, K., Wada, M. \& Ohno, H. Cellulose dissolution with polar ionic liquids under mild conditions; required factors for anions. Green Chem. 10, 44-46 (2008).

29 Ho, F. F.- L., Kohler, R. R. \& Ward, G. A. Determination of molar substitution and degree of substitution of hydroxypropyl cellulose by nuclear magnetic resonance spectroscopy. Anal. Chem. 44, 178-181 (1972).

30 Lee, D.- S. \& Perlin, S. ${ }^{13}$ C NMR spectral and related studies on the distribution of substituents in 0-(2-hydroxypropyl)cellulose. Carbohydr. Res. 106, 1-19 (1982).

31 Bonhôte, P., Dias, A.- P., Papageorgiou, N., Kalyanasundaram, K. \& Grätzel, M. Hydrophobic, highly conductive ambient-temperature molten salts. Inorg. Chem. 35, 1168-1178 (1996).

32 Huddleston, J. G., Visser, A. E., Reichert, W. M., Willauer, H. D., Broker, G. A. \& Rogers, R. D. Characterization and comparison of hydrophilic and hydrophobic room temperature ionic liquids incorporating the imidazolium cation. Green Chem. 3, 156-164 (2001).

33 Branco, L. C., Rosa, J. N., Ramos, J. J. M. \& Afonso, C. A. M. Preparation and characterization of new room temperature ionic liquids. Chem. Eur. J. 8, 3671-3677 (2002).

34 de Vries, H Rotatory power and other optical properties of certain liquid crystals. Acta Crystallogr. 4, 219-226 (1951).

35 Nishio, Y., Tani, Y., Kimura, N., Suzuki, H., Ito, S., Yamamoto, M., Harkness, B. R. \& Gray, D. G. Fluorescence emission and conformation of 6-O- $\alpha-(1-N a p h t h y l m e t h y l)-2,3-$ di-O-pentylcellulose in dilute solution. Macromolecules 28, 3818-3823 (1995).

36 Kuse, Y., Asahina, D. \& Nishio, Y. Molecular structure and liquid-crystalline characteristics of chitosan phenylcarbamate. Biomacromolecules 10, 166-173 (2009).

37 Modaressi, A., Sifaoui, H., Mielcarz, M., Domanska, U. \& Rogalski, M. Influence of the molecular structure on the aggregation of imidazolium ionic liquids in aqueous solutions. Colloids Surf. A: Physicochem. Eng. Aspects 302, 181-185 (2007).

38 Hormnirun, P., Sirivat, A. \& Jamieson, A. M. Complex formation between hydroxypropylcellulose and hexadecyltrimethylamonium bromide as studied by light scattering and viscometry. Polymer 41, 2127-2132 (2000).

39 Drummond, C. J., Albers, S. \& Furlong, D. N. Polymer-surfactant interactions: (hydroxypropyl)cellulose with ionic and non-ionic surfactants. Colloids Surfaces 62, 75-85 (1992), and references cited therein.

40 Cammarata, L., Kazarian, S. G., Salter, P. A. \& Welton, T. Molecular states of water in room temperature ionic liquids. Phys. Chem. Chem. Phys. 3, 5192-5200 (2001). 